How has all this come about? The most striking lesson to be learned from the Geddes Report is the great value of public discussion. The report on shipbuilding research in 1962 by the old Department of Scientific and Industrial Research (now merged in the Ministry of Technology) seems to have been particularly effective in giving the industry a grasp of the problem of designing modern engines. The sense of indignity engendered by a critical report can evidently work where common sense may fail. It is also plain how much can be done to revivify an industry by encouraging co-operative research financed. chiefly by industry, but with backing from the Government. In British shipbuilding, the better spirit in the research associations is, so far, the most tangible sign that things may yet go well. The British Government, which has in the past tended to scorn the research associations it originally helped to create, ought to read with great care the passages in the Geddes Report on co-operative research.

\section{TEACHING FOR EXPORT}

M UCH good will come from the institution which the United Kingdom Ministry of Overseas Development and the Nuffield Foundation have chosen to call by the delicious name of CREDO ("Centre for Educational Development Overseas"). The intention is to provide a headquarters (in London) from which the use of new teaching materials developed in Britain and similar countries can be fostered in nations overseas. Inevitably, the first customers will be the nations known as underdeveloped, though it is only proper to remember that, in education, all nations are in some sense underdeveloped. CREDO will work with materials and methods in all specialities, from English language to physics, though the greatest demand is likely to be for parts of the school curriculum in science. With luck, the institution should survive the three years covered by the first allocation of funds-especially if by then the Ministry of Overseas Development has the funds to sustain the good works it is always talking about.

The need for a mechanism for channelling educational aid to nations overseas should not, of course, obscure the difficulties of these operations. For one thing, it is necessary to avoid suspicions of neo-colonialism. Especially in dealings with African nations, CREDO will have to tread warily. It is understandable that many nations should fear that the old slogan about trade following the flag has now been replaced by a link between education and political influence. The sponsors of CREDO are mercifully seized of this danger. They seem also to acknowledge the difficulties of transplanting educational methods and materials from one environment to some other. The difficulty is that a sensitively designed curriculum is an intellectual and social entity in which should ideally participate whole communities of teachers. It follows that the best way to export teaching is to enable nations wishing to improve themselves to study, mimic and adapt those parts of practice elsewhere that seem to be desirable. By this test, CREDO will be most successful if it can avoid thinking of itself as an export agency; the ideal is that it should assist developing nations to create for themselves machinery by which curriculum development can be begun and then sustained.

\section{IDEAS AND WORDS}

\section{Scientific Psychology}

Principles and Approaches. Edited by Benjamin B. Wolman and Ernest Nagel. Pp. xv +620. (Now York and London: Basic Books, 1965.) 70s.

NCE upon a time philosophy gave birth to a large family of sciences. One by one they broke away from the maternal apron-strings. For psychology, however, the youngest of these, the breakaway proved a mixed blessing. No sooner did she walk alone than she found her footsteps dogged by seducers: behaviourism, reductionism, positivism, and a host of others.

In the face of these perils, and on the initiative of $\mathrm{Dr}$. B. B. Wolman, the editor of Scientific Psychology, thirty scholars have been mobilized to advise on the defensive measures to be taken. At the outset, his co-editor, Ernest Nagel, counsels a return to the security of mother philosophy.

Dr. Wolman hopes that the compendium will establish a science of science, defined as the study, by scientific methods, of "systems of propositions which convey a certain kind of knowledge". This task he considers to be different from the psychology, sociology or history of science. Prof. Arne Naess takes up his challenge to create a metascience, and gives us a lively critique of the idea that scientists, in the course of their work, can be studied as if they were rats in mazes. For, he remarks. unlike the psychologist who himself constructs the mazes into which the rats are placed, the metascientist may have no idea of the 'maze' in which his 'rat' finds itself. That is, he may know little of the problems, goals, culs-desac or rewards of the scientist. Prof. Naess concludes that the metascientist cannot observe science from the outside. He must somehow participate in the labours of those who constitute his subject-matter. This participation is of special significance to psychologists because they have a similar relationship to their subject-matter: human beings.

Other contributors are concerned with philosophical or logical aspects of psychological issues. Outstanding among these are Jean Piaget and J.-B. Grize, who discuss the basis of genetic epistemology. This is a branch of psychology which traces, stage by stage, the natural development in the individual child of those mental operations which eventually come to grips with the essential concepts of mathematics and physical science. Piaget turns the tables on the editors by suggesting that a sound philosophy must rest on empirical psychology, rather than vice versa, for the concepts of mathematics and physics do not spring ready-made from the mind, nor are they abstracted from the objects of observation. They always presuppose a series of interactions between the thinking subject and the object of his thought. The study of child development thus poses questions which converge with the great problems of epistemology and the philosophy of the sciences: How is logic related to language? What is causality ? Is number an intuitive concept? How is the idea of speed related to that of time? And so on.

Most of the contributors either limit themselves to philosophical problems as such or to particular psychological systems. Among the former are G. J. Warnock, who writes on logical analysis and the nature of thought, and D. M. Armstrong, who expounds a theory of percep. tion. The latter are excessively represented by theorists of learning, including an admirable chapter by B. F. Ritchie, who is troubled about tho vagueness of learning theory. Prof. Ritchie proposes two axioms for metascience. One relates to the scientist whose confidence in his theory is directly proportionate to the degree to which he cherishes it. The other applies to the scientist who, on discovering a fact which contradicts his theory, revises his theory to render it untestable.

The chapters vary in quality. Some are written in an obscure prose exemplified by the title of the editor's final 